\section{URLs}

sseB http://www.ncbi.nlm.nih.gov/ entrez/query.fcgi?db=gene\&cmd=R etrieve\&dopt=Graphics\&list_ uids $=1254057$

ssaG

http://www.ncbi.nlm.nih.gov/entrez/ query.fcgi?db=gene\&cmd=Retrieve \&dopt=Graphics\&list_uids=1252924 ssaH

http://www.ncbi.nlm.nih.gov/entrez/ query.fcgi?db=gene\&cmd=Retrieve \&dopt=Graphics\&list_uids=1252925 ssal

http://www.ncbi.nlm.nih.gov/entrez query.fcgi?db=gene\&cmd=Retrieve \&dopt=Graphics\&list_uids=1252926

BACTERIAL PATHOGENESIS

\title{
Polar projections
}

A recent report published in the EMBO Journal describes the molecular analysis of the type III secretion system (TTSS) encoded by the Salmonella pathogenicity island 2 (SPI2).

TTSSs are molecular machines that are used by pathogenic Gramnegative bacteria to inject microbial virulence proteins into host cells. Now, Michael Hensel and co-workers have analysed the structure and composition of the SPI2-TTSS, using high-resolution electron microscopy (EM) techniques. On induction of the SPI2 genes, irregular, needlelike structures formed on the surface of Salmonella enterica serovar Typhimurium, with each bacterium usually expressing a single SPI2encoded appendage at the pole of the cell. Each protrusion consisted of an inner cylinder that spanned the bacterial cell envelope, and the extracellular part of this cylinder was sheathed by irregular deposits of the pore-forming translocon proteins SseB, SseC and SseD.

Analysis of mutant strains identified the putative structural components of this inner cylinder: $s s a G$, $s s a H$ and $s s a I$ mutant strains did not form polar appendages, were unable to translocate effector proteins and were defective in intracellular replication - a process that is dependent on a functional SPI2-TTSS. Also, in sseB mutant strains, SseC and SseD were diffusely distributed on the bacterial cell surface and were not associated with the surface protru- sions. In view of these observations, the authors propose that SseB might be crucial for the functional assembly of these translocon proteins.

EM analysis of SPI2-dependent structures in vivo provided a fascinating first glimpse of the TTSS 'in action' in intracellular bacteria. Bacterial surface projections either contacted or extended beyond the enclosing phagosome membrane.

Finally, Hensel and his team showed that, in agreement with previous studies, the acidic environment of the phagosome was required for functional SPI2-TTSS assembly, but the expression of the SPI2 genes was $\mathrm{pH}$ independent.

It is noteworthy that, compared with the sparse distribution of the SPI2-TTSS, the SPI1-encoded TTSS (another TTSS possessed by S. enterica) is expressed abundantly over the cell surface. The authors

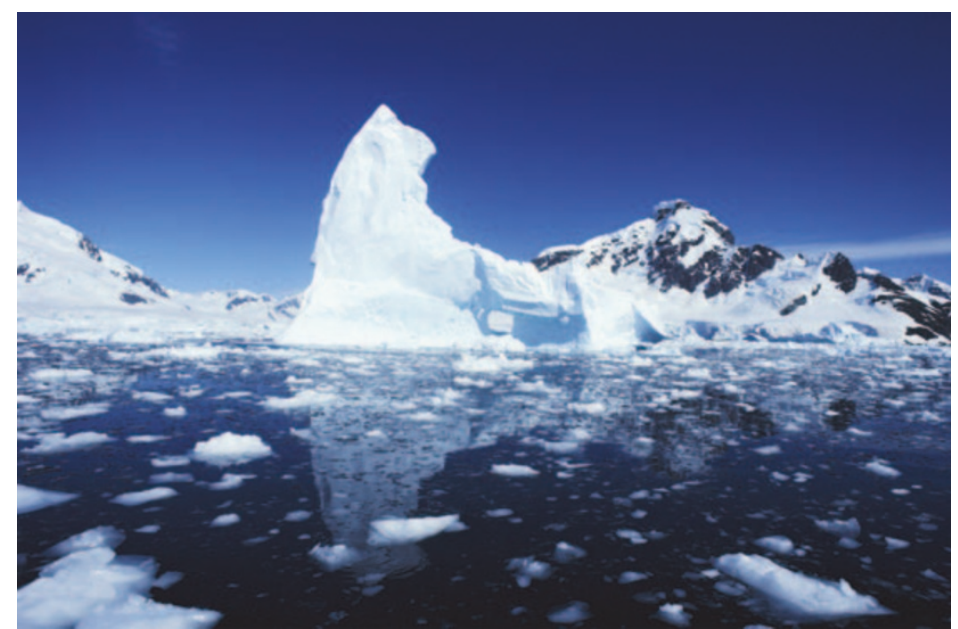

reason that this might be related to the different functions of these two molecular machines. The structures encoded by SPI1 mediate the invasion of target cells by extracellular bacteria. The expression of numerous injectisomes on the surface of S. enterica would increase the likelihood of contact between the bacteria and its target cell. On the other hand, the SPI2-TTSS is expressed by bacteria that are enveloped in the phagosome. Under these conditions, a single TTSS complex would be sufficient to translocate effector proteins.

Shannon Amoils

\section{(1) References and links} ORIGINAL RESEARCH PAPER Chakravortty, D. Rhode, M., Jager, L., Deiwick, J. \& Hensel, M. Formation of a novel surface structure encoded by Salmonella Pathogenicity Island 2. EMBO J. May 2005 (doi: 10.1038/sj.emboj.7600676) 